Article

\title{
Effects of On-Site PV Generation and Residential Demand Response on Distribution System Reliability
}

\author{
Sıtkı Güner ${ }^{1}\left(\mathbb{D}\right.$, Ayşe Kübra Erenoğlu ${ }^{2}$, İbrahim Şengör ${ }^{3}\left(\mathbb{D}\right.$, Ozan $_{\text {Erdinç }}^{2}$ and \\ João P. S. Catalão ${ }^{4, *}$ \\ 1 Department of Electrical and Electronics Engineering, Faculty of Engineering and Architecture, \\ Istanbul Arel University, Tepekent-Buyukcekmece, 34537 Istanbul, Turkey; sguner@arel.edu.tr \\ 2 Department of Electrical Engineering, Faculty of Electric-Electronics, Yildiz Technical University \\ Davutpasa Campus, Esenler, 34220 Istanbul, Turkey; erenayse@yildiz.edu.tr (A.K.E.); \\ oerdinc@yildiz.edu.tr (O.E.) \\ 3 Department of Electrical and Electronics Engineering, Faculty of Engineering and Architecture, Izmir Katip \\ Çelebi University, Çiğli, 35620 Izmir, Turkey; ibrahim.sengor@ikc.edu.tr \\ 4 Faculty of Engineering of the University of Porto and INESC TEC, 4200-465 Porto, Portugal \\ * Correspondence: catalao@fe.up.pt
}

Received: 23 August 2020; Accepted: 3 October 2020; Published: 12 October 2020

\begin{abstract}
In the last few decades, there has been a strong trend towards integrating renewable-based distributed generation systems into the power grid, and advanced management strategies have been developed in order to provide a reliable, resilient, economic, and sustainable operation. Moreover, demand response (DR) programs, by taking the advantage of flexible loads' energy reduction capabilities, have presented as a promising solution considering reliability issues. Therefore, the impacts of combined system architecture with on-site photovoltaic (PV) generation units and residential demand reduction strategies were taken into consideration on distribution system reliability indices in this study. The load model of this study was created by using load data of the distribution feeder provided by Bosphorus Electric Distribution Corporation (BEDAS). Additionally, the reliability parameters of the feeder components were determined based on these provided data. The calculated load point and feeder side indicators were analyzed comprehensively from technical and economic perspectives. In order to validate the effectiveness of the proposed structure, four case studies were carried out in both DigSILENT PowerFactory and MATLAB environments.
\end{abstract}

Keywords: distribution system; PV generation; reliability; residential demand response programs

\section{Introduction}

\subsection{Motivation and Background}

Power system reliability can be evaluated as one of the most important factors in the operation, planning, and design process of the utility network and sometimes state-regulated area. This complicated architecture including numerous different types of loads, transformers, substations, switching components, and long transmission lines targets to supply hundreds of millions of electricity consumers' daily needs in a reliable fashion. The North American Electric Reliability Corporation (NERC), one of the most widely-known institutions, has provided a definition for reliability as [1] "the ability to meet the electricity needs of end-use customers even when unexpected equipment failures or other factors reduce the amount of available electricity". Additionally, from European energy providers' viewpoint, European Network of Transmission System Operators (ENTSO-E) provided the widely-known definition as "a general term encompassing all the measures of the ability of the system, 
generally given as numerical indices, to deliver electricity to all points of utilization within acceptable standards and in the amounts desired" [1].

Recently, increasing environmental concerns and growing demand paved the way for expanding the portion of renewable-based energy systems on the generation side, ensuring reliable, sustainable, and resilient power grid operation [2]. In order to reduce greenhouse gas emissions, there have been great attempts and incentives within the context of signing protocols by most of the countries. Among them, Malta and Sweden target to increase the installed renewable energy resources (RESs) capacity respectively by $10 \%$ and $49 \%$ [3]. The European Council has agreed on the 2030 climate and energy framework, including targets and policy objectives. Particularly, reducing greenhouse gas emission at least by $40 \%$ compared to the level of 1990, increasing renewable energy consumption rate at least $32 \%$, and improving energy efficiency level by $32.5 \%$ are the key targets for 2030 [4]. According to the Renewable Energy Roadmap (Remap) 2030 [5], the world's biggest energy consumer, China, is aiming to increase the share of renewables in the power sector from $20 \%$ to $40 \%$ by 2030 . It is obvious that it requires a market reform as well as significant growth in transmission and grid capacity.

There are many types of renewable energy resources in the energy sector, such as wind, solar, hydro, and biomass [5]. Among them, photovoltaic (PV) generation is accepted as one of the most prominent sources, and its globally installed capacity is increasing day by day considering technological developments and economic achievements, especially for implementing at the scale of distributed generation (DG). This green resource can be installed at a large-scale in utility facilities or at a small-scale at the end-users' premises with the aim of meeting the local demand. It is to be highlighted that grid-connected units can play a key role in system operation, especially in case of failures in any part of the system and in providing reliability improvement by decreasing unsupplied power.

From the other perspective, demand side has also witnessed spectacular changes in its architecture, e.g., prosumers (consumers also with on-site production facilities) with flexible loads are strongly encouraged to alter their load profiles for the purpose of accomplishing particular objectives such as load leveling, reliability enhancement, and voltage regulation within the paradigm of smart grid. Unlike the conventional network operation in which expanding generating capacity means to increase reserve margin and reliability factor [6], modern structure turns its perspective from the power supply side to the demand side. A conceptual definition of demand response (DR) by US Energy Information Administration viewpoint is as follows: "Demand-side management (DSM) programs consist of the planning, implementing, and monitoring activities of electric utilities which are designed to encourage consumers to modify their level and pattern of electricity usage" [7]. It is worthy to indicate that new approaches play a critical role in electrical system planning while considering its sophisticated structure, and the last decade has seen a growing trend towards incorporating DR strategies into operational stages to increase network performance and quality of services. Here, smart households that can alter their internal operation in an optimized way, especially if a home energy management system (HEM) exists, have further capability to enhance effective implementation of residential DR, which is an area where more implementations have been provided recently.

\subsection{Literature Review}

In recent years, integrating modular RESs into the power system as well as demand side management implementations have been widely investigated in the literature to cope with reliability issues and increase the quality of services. In this respect, Yoo et al. [6] proposed a reliability-based DR program in which traditional DR programs such as summer vacation period DR program, direct load control, and demand bidding were reconstructed considering the system requirements. The presented structure consisting of consumer data management and program operation parts aided network operation, especially in emergency conditions, by trading emergency DR resources instantly.

Wu et al. [8] examined the effect of aggregated electric water heaters (EWHs) DR capability and their load shifting performance analysis, especially in peak hours for the purpose of achieving reliability improvement. According to the results, it should be highlighted that the reliability indices 
were enhanced thanks to the provided certain amount of operating reserve by aggregated EWHs. The optimization-based strategy also aimed to reduce end-users' total cost while maintaining the comfort levels. In order to improve the reliability indices in modern power systems, controllable demand sources were taken into consideration in [9] as an alternative for extra generation (reserves). On the other hand, DR implementation affects the generating system reliability. In [10], the short-term reliability model of DR capacity was proposed using a multi-state continuous-time Markov chain model.

A stochastic security constrained scheduling approach integrating DR model was presented in [11] with the objective of determining an optimal strategy for the independent system operator considering market conditions, system security, and reliability needs as well as air pollution. Moreover, total operational cost was also aimed to be minimized by implementing an efficient DR program through mixed-integer linear programming. Goel et al. [12] conducted a study in which the effects of stochastic demand side load shifting approach on electricity price volatility and reliability issues were examined by using optimal power flow combined with some reliability evaluation techniques in restructured power systems. Additionally, in [13], the impacts of real-time price-based DR application on system reliability were investigated by taking into account nodal price volatility and potential DR resources. The optimal power system operation was guaranteed within the generation and the transmission constraints. However, no attempt was made to investigate RES-based generating unit's impact on the power grid reliability indices in studies [12,13].

Li et al. [14] created a model for a micro-grid including loads, distribution generators, and energy storage systems (ESSs) combined with possible DR strategies for reliability evaluation in a distribution system unlike the obsolete conventional methods. RES penetrations as well as charging/discharging strategies of ESSs were taken into consideration evaluating their impacts on the operational perspective. In order to validate the effectiveness of the proposed scheme, sequential Monte Carlo simulation and minimal path method were used.

The effects of the DR program on the reliability assessment of a microgrid was also studied in [15] considering its complicated architecture. The authors in [16] presented a new bus weighting methodology with the aim of optimizing system operation, especially in case of unfavorable weather conditions or peak demand periods. It is significant to indicate that expected interruption costs were decreased approximately by $20 \%$ thanks to the proposed framework, in which it is possible to distribute the total system's DR requirement in critical loading events.

Su et al. [17] proposed a reliability assessment model considering aging period of conventional power equipment for determining reliability of the distribution network also including PV generation. In [18], the climate change effects were taken into account for assessing reliability of the PV integrated power systems. Several positive and negative impacts of the roof-top PV systems on the reliability of distribution transformers were identified in [18]. The negative impacts of the roof-top PV systems according to penetration level were presented in [19].

Hybrid systems usually increase power system reliability, and, in this manner, Raghuwanshi and Arya [20] studied the impacts of hybrid systems having different combinations of diesel/PV/battery systems on power system reliability. Markov model and frequency-duration (F-D) reliability techniques were used for assessing reliability indices, namely, loss of load probability (LOLP), expected energy not supplied (EENS), and mean downtime (MDT). In [21], optimum restoration strategies were generated together with the consideration of distribution system reliability assessment considering hybrid renewable DG systems. A time-sequential Monte Carlo simulation was used for evaluating distribution system reliability in the mentioned study.

Cao et al. [22] examined the effects of wind power integration on the reliability assessment of power systems. The authors in [23] constructed a power system reliability model by taking highly integrated wind farms into account and analyzed the results by an IEEE-RTS79 based case study through Monte Carlo simulation technique. However, any types of DR programs combined with RES integration under reliability assessment architecture were not considered in [22,23]. 


\subsection{Contributions and Organization of the Paper}

A mathematical model for reliability indices improvement in power system architecture including on-site PV generation and efficient DR strategies is proposed in this study. The main objective of the propounded concept is to increase system reliability performances by reducing the impact of failures on end-users' power supply during the critical day periods. The contributions of the study can be detailed as follows:

- Both the management of DR and DG penetration are crucial tasks for the improvement of distribution system reliability; hence, this paper presents the contribution of both methods in terms of reliability level of the system.

- The results of this study by modeling the distribution system and the PV generation unit with real data may provide guidance for more effective integration of PV generation from reliability enhancement perspective.

The rest of paper is organized as follows: the relevant basic mathematical background of reliability indices is detailed in Section 2. Afterwards, Section 3 provides the declarations of case studies and the discussion of results. Finally, concluding remarks and future work are presented in Section 4.

\section{Reliability Assessment Approach}

This part discusses the generally known facts regarding the reliability assessment for the sake of a complete problem overview. One of the main targets of distribution system operators is to supply end-users' demand with acceptable continuation and power quality. However, it is sometimes possible to interrupt large parts of the load point's electrical demand due to small-scale faults in any equipment such as lines, cables, transformers, breakers, switches, busbars, and relays.

Therefore, the measurements of outage rates and power interruption duration should be taken into account in this sophisticated architecture to determine reliability performance standards [24].

Load point indices and system reliability indices are frequently used parameters [25] in the literature that are essential in planning, management, and operation stages from the master controller's viewpoint. The fundamental below-mentioned criteria to calculate reliability performance of distribution feeder at the load point are as follows [26]:

- Load point failure rate $(\lambda)$

- The average outage time $(r)$

- Average annual unavailability or outage $(U)$

The basic reliability parameters of a distribution system are described in Equations (1)-(3) in which $i$ shows the index of the components that are assumed to be connected in series between the source and the load point, in terms of failure.

$$
\begin{gathered}
\lambda_{s}=\sum_{i} \lambda_{i} \\
U_{s} \cong \sum_{i} \lambda_{i} r_{i} \\
r_{s}=\frac{U_{s}}{\lambda_{s}} \cong \frac{\sum_{i} \lambda_{i} r_{i}}{\sum_{i} \lambda_{i}}
\end{gathered}
$$

It is to be highlighted that load point indices have importance for individual end-users' perspective but are not sufficient for evaluating the whole system performance. Therefore, system reliability indices are additionally used in this study by taking into account the number and the load of end-users connected at each load point in the system $[27,28]$. The most commonly used criteria for measuring distribution system reliability performances are categorized into two parts as follows: 


\subsection{Interruption Indices}

System Average Interruption Frequency Index (SAIFI) and System Average Interruption Duration Index (SAIDI) are the most widely used indices by utility companies in order to reach their targets in terms of customer satisfaction, service restoration, and quality of services [29]. Throughout this study, these mentioned indicators are used for assessing the reliability improvements.

SAIFI gives the average number of interruptions per end-user per year in the system and can be decreased by reducing outages at the load points [27]. SAIFI is represented as given in Equation (4) where $i$ indicates load point, while $N_{i}$ is the total number of end-users served.

SAIDI index is expressed in Equation (5) that means the average interruption duration per end-user experienced during the year [30]. It is possible to achieve improvements in SAIDI by reducing failure restoration times with effective crew management strategies.

$$
\begin{gathered}
\text { SAIFI }=\frac{\sum_{i} \lambda_{i} N_{i}}{\sum_{i} N_{i}} \\
\text { SAIDI }=\frac{\sum_{i} U_{i} N_{i}}{\sum_{i} N_{i}}
\end{gathered}
$$

\subsection{Energy Oriented Indices}

The most commonly used load-energy-oriented reliability criterion is the annual total energy not supplied (ENS). There are also energy-oriented indices such as average energy not supplied (AENS) and average customer curtailment index (ACCI), but ENS is used to determine loss of load capacity of the distribution system in this study. This reliability indicator is formulated as in Equation (6), where $L_{i}$ indicates the demand at $i$ th load point.

$$
E N S=\sum_{i} U_{i} L_{i}
$$

\section{Test and Results}

\subsection{Input Data of Distribution System}

The network topology of the distribution system consisting of approximately $40 \%$ residential and $60 \%$ commercial load is depicted in Figure 1. In this modified framework, daily load curves were obtained from Bosphorus Electric Distribution Corporation (BEDAS) in which the feeder included nine load-points each having different consumption and transformers as 34.5/0.4 kV. There were 3503 consumers included in the feeder. The connection between utility grid and feeder was also provided by $154 / 34.5 \mathrm{kV}$ transformer. In order to make realistic assumptions and observe the effect of PV power plant on the reliability improvement, a prosumer (factory with on-site PV generation) was taken into account as in LP9. The used real radiation data for PV generation were obtained from the National Renewable Energy Laboratory (NREL) [31] by considering the latitude of the region and were normalized in accordance with the ambient temperature. The evaluated radiation data are demonstrated in Figure 2 and validated by comparison of those data with the relevant literature in [32,33]. It should be noted that the radiation data may have changed according to the weather condition based on whether it was a cloudy day or a sunny day. The power demand of load points was procured by both utility grid and PV energy supply unit for providing a reliable and sustainable network. 


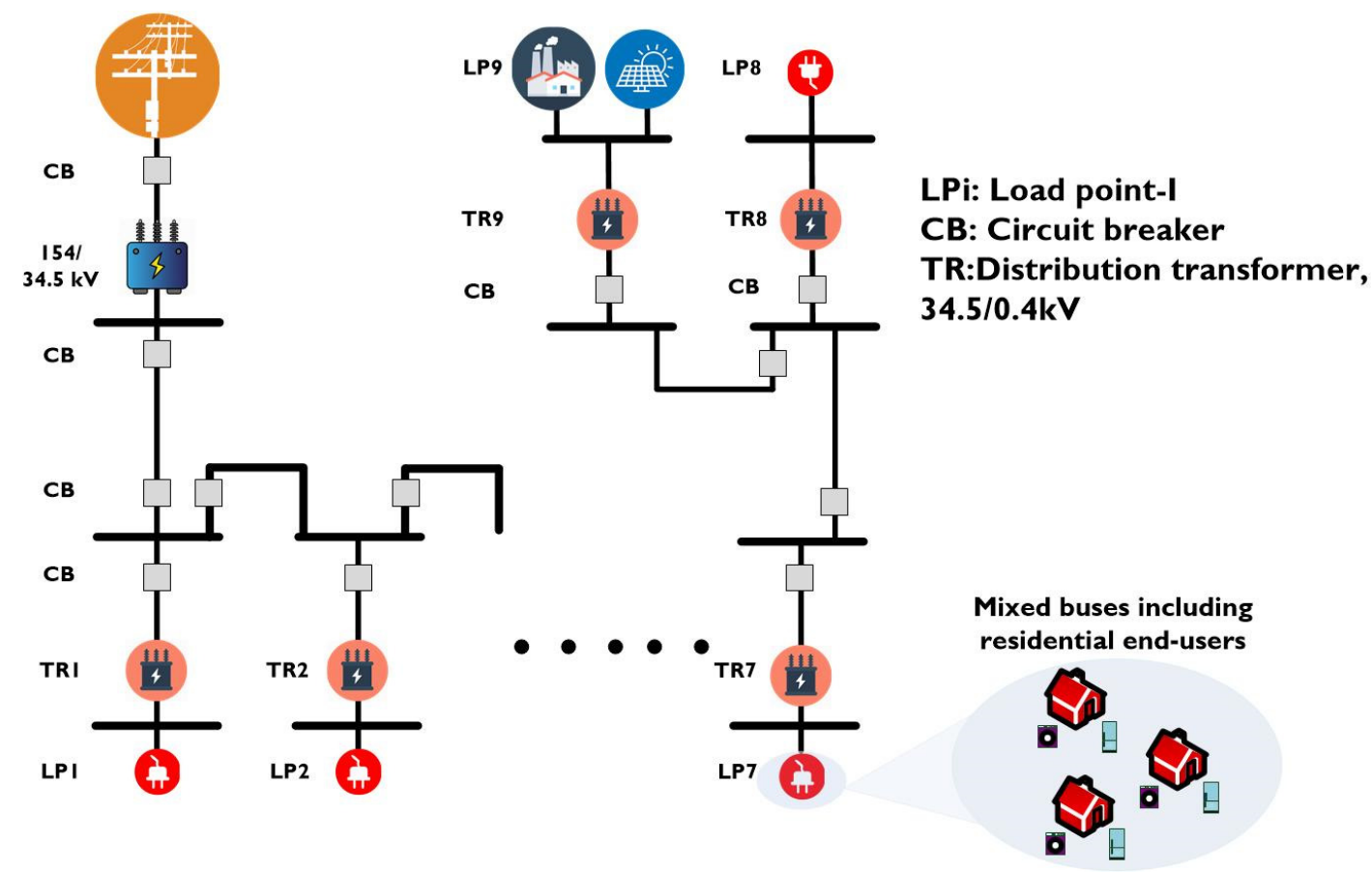

Figure 1. General overview of the distribution system model for the test cases.

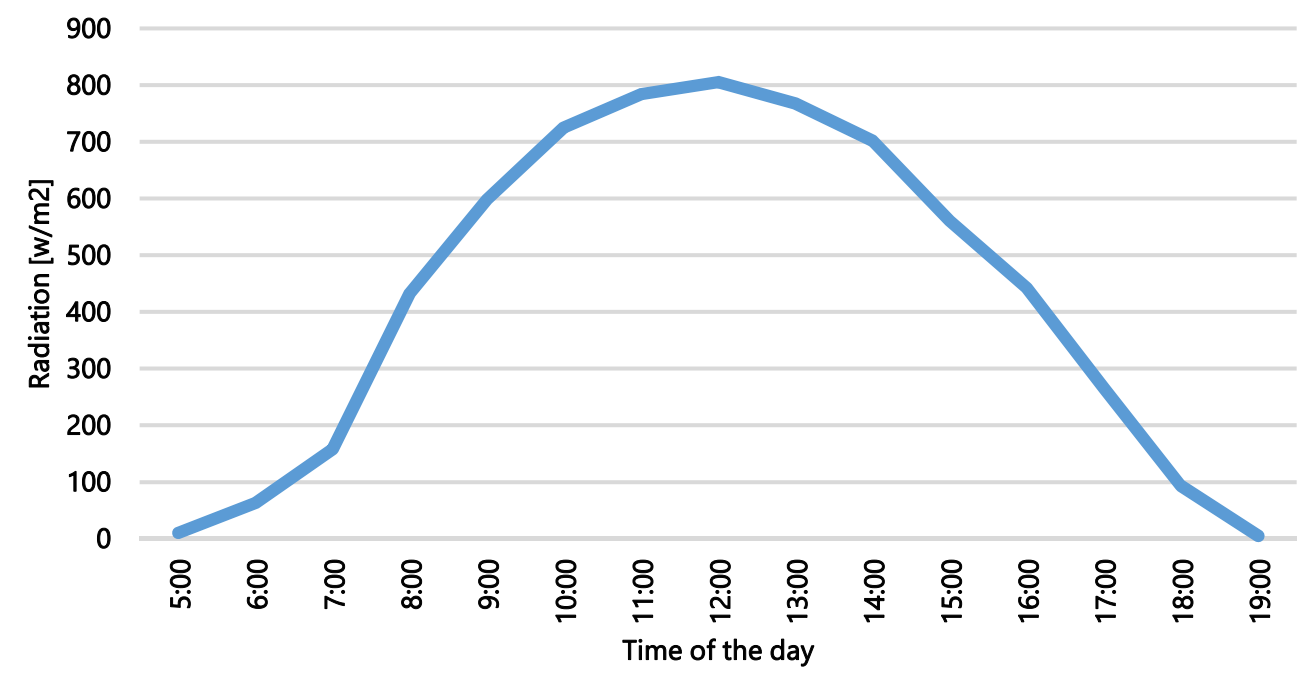

Figure 2. The used radiation data taken from National Renewable Energy Laboratory (NREL).

The daily load curve of the distribution feeder was obtained by using provided one year hourly energy consumption data from the distribution company. According to these raw data, the loading pattern of every season on hourly basis was acquired. The peak values of the load curves were 3.52 MVA, 2.93 MVA, and 2.40 MVA for winter, spring, and summer, respectively. The highest amount of consumption occurred in winter periods, and its characteristic was accordingly used in this study for modeling the loads, as shown in Figure 3.

A detailed study was carried out on the above mentioned radial distribution feeder for investigating the impacts of both incorporated PV plant and DR programs, including smart households oriented concepts on system reliability improvement. The system reliability indices were calculated in DigSILENT PowerFactory and MATLAB environments by using the given parameters of distribution system components, as indicated in Table 1. In addition, load point interruption frequency (LPIF), load point interruption time (LPID), and load point energy not supplied (LPENS) criteria were 
also analyzed to evaluate the effects of PV based generation unit and DR on reliability from end-user standpoint.

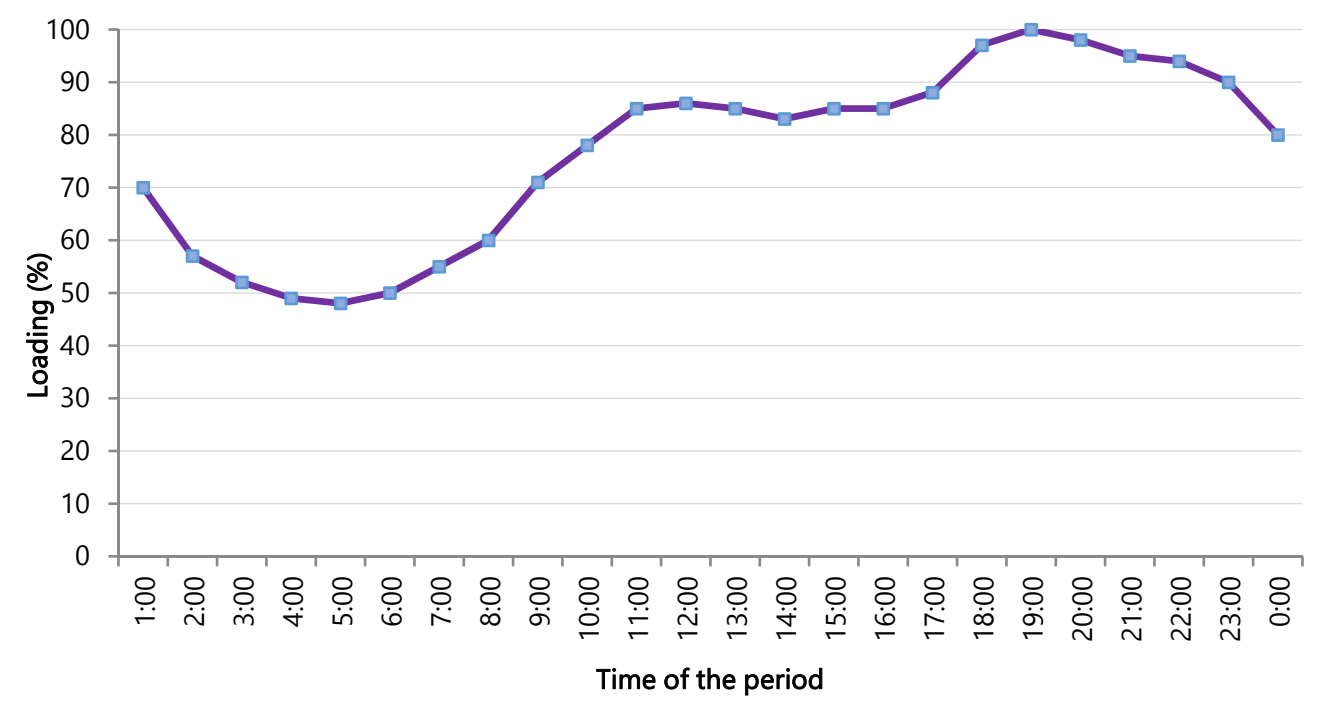

Figure 3. Daily load curve of the distribution feeder for winter.

Table 1. Failure rate and mean time to repair parameters of distribution feeder components.

\begin{tabular}{ccccc}
\hline & External Network & $\begin{array}{c}\text { Distribution Transformer } \\
(\mathbf{3 4 . 5 / 0 . 4} \mathbf{~ k V )}\end{array}$ & Bus and Circuit Breaker & Cable \\
\hline $\boldsymbol{\lambda}(1 /$ year $)$ & 0.1 & 0.5 & 0.25 & 0.75 \\
$\mathbf{r}($ hr/year $)$ & 8.7 & 3 & 4 & 4 \\
\hline
\end{tabular}

\subsection{Case Studies and Results}

In order to validate the effectiveness of the proposed model, four different case studies were conducted in this study as follows:

- Case-1: LP9 was only considered as load, i.e., PV based generation unit and DR were out of concept. Additionally, it was used as the reference base case for showing the reliability improvement of other cases.

- Case-2: PV system was incorporated as DG for backup power supply.

- Case-3: In addition to PV based generation unit, 10\% demand reduction was also implemented through DR program.

- Case-4: In addition to PV based generation unit, 20\% demand reduction was also implemented through DR program.

In Case-1, PV based generation unit and demand reduction were not taken into consideration, i.e., the load demand of LP9 was supplied by only external grid. Thus, the other case studies could be analyzed thoroughly in terms of reliability improvement based on the reference condition. The feeder reliability indices (SAIFI, SAIDI, ENS) and the load point reliability indices (LPIF, LPID, LPENS) were calculated in MATLAB environment for base case, as indicated in Table 2.

The feeder reliability indices (SAIFI, SAIDI, ENS) and the load point reliability indices (LPIF, LPID, LPENS) were calculated in MATLAB environment for Case-2, as indicated in Table 3 . The impacts of DG power supply can be clearly examined in terms of improvement in indicators, as stated in Table 4 . In total, $7.02 \%$ and more improvement was achieved in SAIFI and SAIDI indices, while $13.72 \%$ was achieved in ENS. On the other hand, higher load reliability indices were obtained for the points near the LP9. For example, LPIF improvement was $17.71 \%$ at LP7, while it was $52.10 \%$ at LP9. It is worth 
noting that PV based generation units can even supply energy needs of end-users in case of any failure, and they may also aid to provide a sustainable and reliable electrical grid in general if some rare cases are neglected for a properly monitored and managed grid structure.

Table 2. Calculated reliability indices for Case-1.

\begin{tabular}{|c|c|c|c|c|c|c|c|c|c|c|c|}
\hline \multirow{2}{*}{\multicolumn{2}{|c|}{$\begin{array}{c}\text { Feeder } \\
\text { Reliability } \\
\text { Indices }\end{array}$}} & \multirow{3}{*}{$\begin{array}{c}\text { Load Point } \\
\text { Reliability } \\
\text { Indices }\end{array}$} & \multicolumn{9}{|c|}{ Load Points } \\
\hline & & & LP1 & LP2 & LP3 & LP4 & LP5 & LP6 & LP7 & LP8 & LP9 \\
\hline $\begin{array}{l}\text { SAIFI } \\
\left(\frac{f}{c-y}\right)\end{array}$ & 5.84 & & 2.92 & 3.92 & 4.92 & 5.92 & 6.92 & 7.92 & 8.92 & 9.92 & 11.17 \\
\hline $\begin{array}{c}\text { SAIDI } \\
\left(\frac{h}{c-v}\right)\end{array}$ & 23.32 & $\operatorname{LPID}\left(\frac{h}{c-y}\right)$ & 11.64 & 15.64 & 19.64 & 23.64 & 27.64 & 31.64 & 35.64 & 39.64 & 44.64 \\
\hline $\begin{array}{l}\text { ENS } \\
\left(\frac{\mathrm{MWs}}{\mathrm{v}}\right)\end{array}$ & 63.64 & LPENS $\left(\frac{\mathrm{MWs}}{\mathrm{y}}\right)$ & 1.06 & 17.74 & 3.27 & 8.78 & 2.32 & 2.68 & 10.10 & 9.74 & 5.80 \\
\hline
\end{tabular}

SAIFI: System Average Interruption Frequency Index; SAIDI: System Average Interruption Duration Index; ENS: energy not supplied; LPIF: load point interruption frequency; LPID: load point interruption time; LPENS: load point energy not supplied.

Table 3. Calculated reliability indices for Case-2.

\begin{tabular}{|c|c|c|c|c|c|c|c|c|c|c|c|}
\hline \multirow{2}{*}{\multicolumn{2}{|c|}{$\begin{array}{c}\text { Feeder } \\
\text { Reliability } \\
\text { Indices }\end{array}$}} & \multirow{3}{*}{ 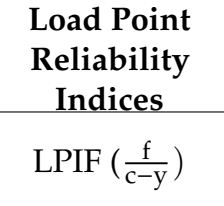 } & \multicolumn{9}{|c|}{ Load Points } \\
\hline & & & LP1 & LP2 & LP3 & LP4 & LP5 & LP6 & LP7 & LP8 & LP9 \\
\hline $\begin{array}{l}\text { SAIFI } \\
\left(\frac{f}{c-y}\right)\end{array}$ & 5.43 & & 2.92 & 3.92 & 4.92 & 5.92 & 6.92 & 7.92 & 7.34 & 5.88 & 5.35 \\
\hline $\begin{array}{l}\text { SAIDI } \\
\left(\frac{h}{c-y}\right)\end{array}$ & 21.69 & $\operatorname{LPID}\left(\frac{h}{c-y}\right)$ & 11.64 & 15.64 & 19.64 & 23.64 & 27.64 & 31.64 & 29.34 & 23.50 & 21.39 \\
\hline $\begin{array}{l}\text { ENS } \\
\left(\frac{\mathrm{MWs}}{\mathrm{y}}\right)\end{array}$ & 54.91 & LPENS $\left(\frac{\mathrm{MWs}}{\mathrm{y}}\right)$ & 1.06 & 17.74 & 3.27 & 8.78 & 2.32 & 2.68 & 8.22 & 5.69 & 3.20 \\
\hline
\end{tabular}

Table 4. Feeder and load point reliability indices improvement for Case-2.

\begin{tabular}{clcccccccccc}
\hline & & \multicolumn{10}{c}{ Load Points } \\
\cline { 3 - 11 } & & LP1 & LP2 & LP3 & LP4 & LP5 & LP6 & LP7 & LP8 & LP9 \\
\hline SAIFI (\%) & 5.43 & LPIF (\%) & 0 & 0 & 0 & 0 & 0 & 0 & 17.71 & 40.73 & 52.10 \\
SAIDI (\%) & 21.69 & LPID (\%) & 0 & 0 & 0 & 0 & 0 & 0 & 17.68 & 40.72 & 52.08 \\
ENS (\%) & 54.91 & LPENS (\%) & 0 & 0 & 0 & 0 & 0 & 0 & 18.61 & 41.58 & 44.83 \\
\hline
\end{tabular}

In order to investigate the combined effects of DR implementation and on-site PV generation on reliability improvement, Case- 3 and Case- 4 were carried out in which the demand reduction capabilities of flexible load by $10 \%$ and $20 \%$ were considered from system and end-user standpoints. Herein, especially for obtaining this DR-based demand reduction from residential end-users, the mentioned households were considered as HEM equipped and therefore could respond to the DR based reduction signals from the system operator automatically. The feeder reliability indices (SAIFI, SAIDI, ENS) and the load point reliability indices (LPIF, LPID, LPENS) were calculated in MATLAB environment for Case- 3 and Case- 4 , as indicated in Tables 5 and 6, respectively. Additionally, the impacts of combined DR implementation and PV generation on feeder and load point reliability indices are shown in Tables 7 and 8 , respectively.

The interaction between the bus based reduction signal and the response of each residential end-user was not considered in detail in this current concept but will be the main topic of a near future optimization-oriented study, similar to a previous study of the authors that did not consider the reliability point-of-view [34]. 
Table 5. Calculated reliability indices for Case-3.

\begin{tabular}{|c|c|c|c|c|c|c|c|c|c|c|c|}
\hline \multirow{2}{*}{\multicolumn{2}{|c|}{$\begin{array}{c}\text { Feeder } \\
\text { Reliability } \\
\text { Indices }\end{array}$}} & \multirow{3}{*}{$\begin{array}{l}\begin{array}{c}\text { Load Point } \\
\text { Reliability } \\
\text { Indices }\end{array} \\
\text { LPIF }\left(\frac{f}{c-y}\right)\end{array}$} & \multicolumn{9}{|c|}{ Load Points } \\
\hline & & & LP1 & LP2 & LP3 & LP4 & LP5 & LP6 & LP7 & LP8 & LP9 \\
\hline $\begin{array}{l}\text { SAIFI } \\
\left(\frac{f}{c-y}\right)\end{array}$ & 7.02 & & 2.92 & 3.92 & 4.92 & 5.92 & 6.92 & 7.92 & 7.11 & 5.84 & 5.35 \\
\hline $\begin{array}{l}\text { SAIDI } \\
\left(\frac{h}{c-y}\right)\end{array}$ & 6.99 & $\operatorname{LPID}\left(\frac{\mathrm{h}}{\mathrm{c}-\mathrm{y}}\right)$ & 11.64 & 15.64 & 19.64 & 23.64 & 27.64 & 31.64 & 28.42 & 23.35 & 21.39 \\
\hline $\begin{array}{c}\text { ENS } \\
\left(\frac{\mathrm{MWs}}{\mathrm{y}}\right)\end{array}$ & 13.72 & LPENS $\left(\frac{\mathrm{MWs}}{\mathrm{y}}\right)$ & 1.04 & 17.32 & 3.19 & 8.58 & 2.27 & 2.62 & 7.83 & 5.64 & 3.20 \\
\hline
\end{tabular}

Table 6. Calculated reliability indices for Case-4.

\begin{tabular}{|c|c|c|c|c|c|c|c|c|c|c|c|}
\hline \multirow{2}{*}{\multicolumn{2}{|c|}{$\begin{array}{c}\text { Feeder } \\
\text { Reliability } \\
\text { Indices }\end{array}$}} & \multirow{3}{*}{$\begin{array}{c}\begin{array}{c}\text { Load Point } \\
\text { Reliability } \\
\text { Indices }\end{array} \\
\text { LPIF }\left(\frac{\mathrm{f}}{\mathrm{c}-\mathrm{y}}\right)\end{array}$} & \multicolumn{9}{|c|}{ Load Points } \\
\hline & & & \multirow{2}{*}{$\begin{array}{l}\text { LP1 } \\
2.92\end{array}$} & \multirow{2}{*}{$\begin{array}{l}\text { LP2 } \\
3.92\end{array}$} & \multirow{2}{*}{$\begin{array}{l}\text { LP3 } \\
4.92\end{array}$} & \multirow{2}{*}{$\begin{array}{l}\text { LP4 } \\
5.92\end{array}$} & \multirow{2}{*}{$\begin{array}{l}\text { LP5 } \\
6.92\end{array}$} & \multirow{2}{*}{$\begin{array}{l}\text { LP6 } \\
7.69\end{array}$} & \multirow{2}{*}{$\begin{array}{l}\text { LP7 } \\
6.90\end{array}$} & \multirow{2}{*}{$\begin{array}{l}\text { LP8 } \\
5.80\end{array}$} & \multirow{2}{*}{$\begin{array}{l}\text { LP9 } \\
5.35\end{array}$} \\
\hline $\begin{array}{l}\text { SAIFI } \\
\left(\frac{f}{c-y}\right)\end{array}$ & 5.13 & & & & & & & & & & \\
\hline $\begin{array}{l}\text { SAIDI } \\
\left(\frac{h}{c-y}\right)\end{array}$ & 20.48 & $\operatorname{LPID}\left(\frac{\mathrm{h}}{\mathrm{c}-\mathrm{y}}\right)$ & 11.64 & 15.64 & 19.64 & 23.64 & 27.64 & 30.71 & 27.58 & 23.18 & 21.39 \\
\hline $\begin{array}{c}\text { ENS } \\
\left(\frac{\mathrm{MWs}}{\mathrm{y}}\right)\end{array}$ & 48.54 & LPENS $\left(\frac{\mathrm{MWs}}{\mathrm{y}}\right)$ & 1.02 & 16.91 & 3.12 & 8.37 & 2.22 & 2.48 & 7.51 & 5.60 & 3.20 \\
\hline
\end{tabular}

Table 7. Feeder and load point reliability indices improvement for Case-3.

\begin{tabular}{cccccccccccc}
\hline & & \multicolumn{10}{c}{ Load Points } \\
\cline { 3 - 11 } & & LP1 & LP2 & LP3 & LP4 & LP5 & LP6 & LP7 & LP8 & LP9 \\
\hline SAIFI (\%) & 9.42 & LPIF (\%) & 0 & 0 & 0 & 0 & 0 & 0 & 20.29 & 41.13 & 52.10 \\
SAIDI (\%) & 9.52 & LPID (\%) & 0 & 0 & 0 & 0 & 0 & 0 & 20.26 & 41.09 & 52.08 \\
ENS (\%) & 18.73 & LPENS (\%) & 1.89 & 2.37 & 2.45 & 2.28 & 2.16 & 2.24 & 22.48 & 42.09 & 44.83 \\
\hline
\end{tabular}

Table 8. Feeder and load point reliability indices improvement for Case-4.

\begin{tabular}{cccccccccccc}
\hline & & \multicolumn{10}{c}{ Load Points } \\
\cline { 3 - 10 } & & LP1 & LP2 & LP3 & LP4 & LP5 & LP6 & LP7 & LP8 & LP9 \\
\hline SAIFI (\%) & 12.16 & LPIF (\%) & 0.00 & 0.00 & 0.00 & 0.00 & 0.00 & 2.90 & 22.65 & 41.53 & 52.10 \\
SAIDI (\%) & 12.18 & LPID (\%) & 0.00 & 0.00 & 0.00 & 0.00 & 0.00 & 2.94 & 22.62 & 41.52 & 52.08 \\
ENS (\%) & 23.73 & LPENS (\%) & 3.77 & 4.68 & 4.59 & 4.67 & 4.31 & 7.46 & 25.64 & 42.51 & 44.83 \\
\hline
\end{tabular}

As a result of Case- 3 and Case- 4 , it is seen that this combined structure helped to achieve a significant amount of contributions into the distribution system operation through increasing reliability indices. It is evident that the improvement was achieved even at LP1 point in LPIF, LPID, and LPENS as shown in Figures 4-6, respectively. The results show that the improvements depended on the location of the load points and on the capacity of the transformer. As a conclusion, it can be said that a respectable reliability improvement was achieved with DG availability and effective DR strategies. 


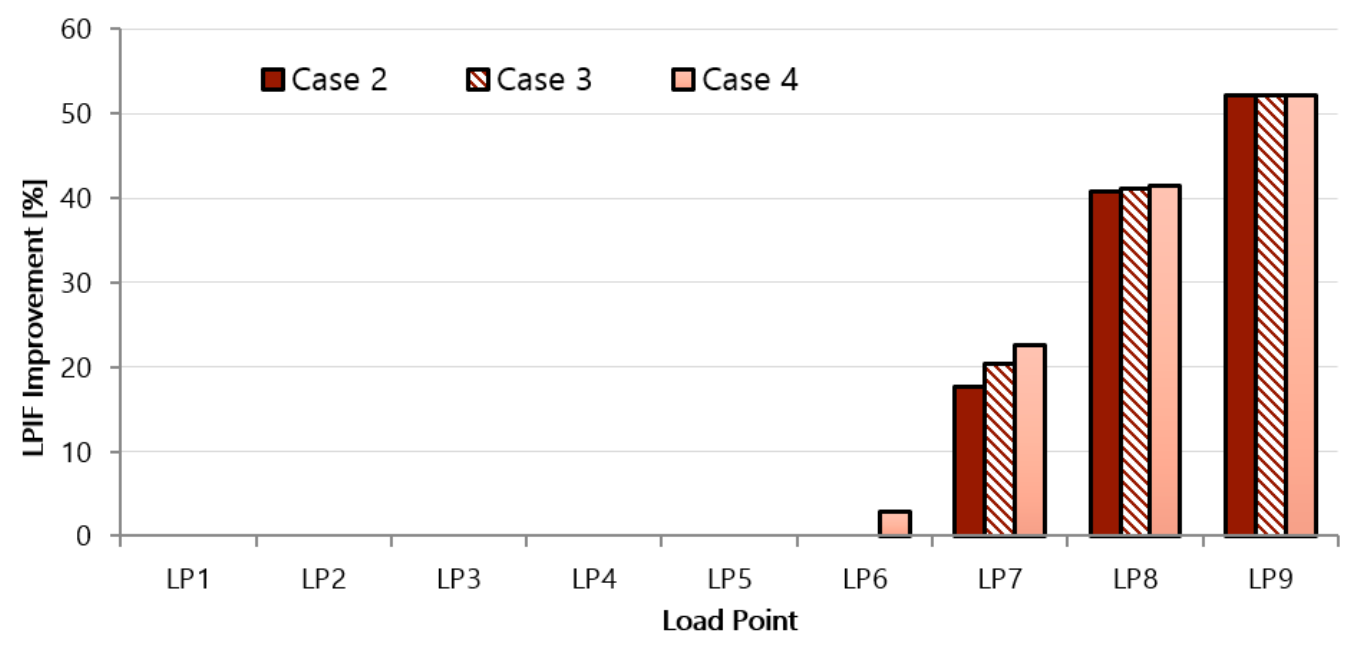

Figure 4. LPIF improvement in load points for case studies compared to Case-1.

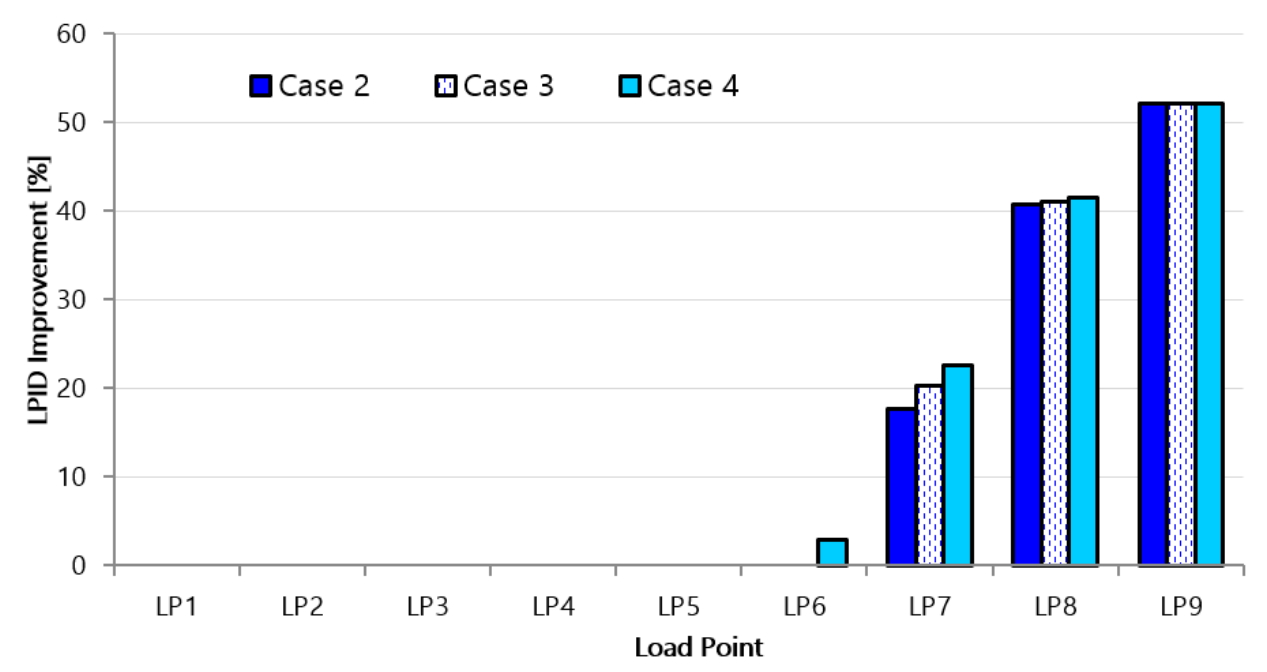

Figure 5. LPID improvement in load points for case studies compared to Case-1.

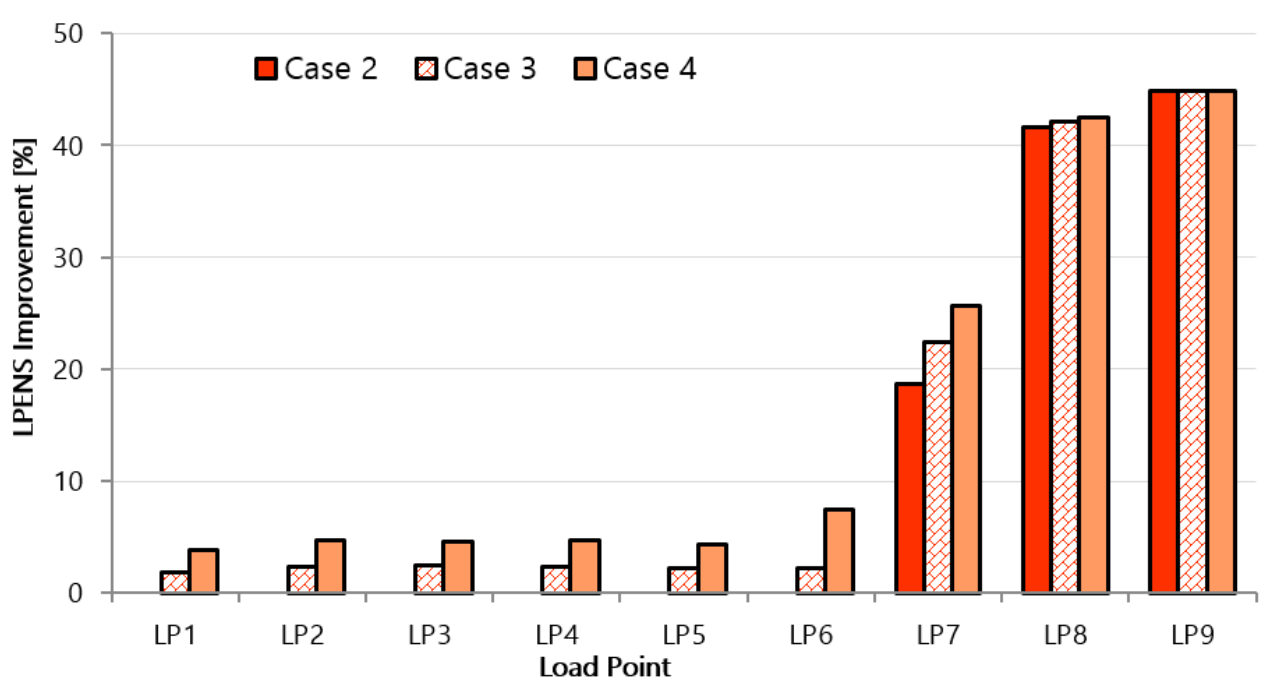

Figure 6. LPENS improvement in load points for case studies compared to Case-1. 


\section{Conclusions}

In this study, the effects of a combined architecture of on-site PV generation and residential DR applications on distribution system reliability were taken into account from system operator and end-user points of view. It should be highlighted that the real data of the distribution feeder were provided by BEDAS, and one of the most widely used reliability parameters was also integrated into DigSILENT PowerFactory and MATLAB programs. Unlike the other valuable literature studies, the proposed structure considered the DG and the DR impacts on reliability simultaneously for the first time in the literature to the best knowledge of the authors.

As it can be seen in this study, the obtained results were reasonable, and the most important thing was that the backup power supply as well as the demand reduction strategies played a key role in terms of reliability improvement in case of any failure at feeder or some other components. According to the case studies, feeder reliability indices were improved by approximately $24 \%$, while load point indices were increased nearly $53 \%$ thanks to the combined structure. As a future study, it is aimed to implement an optimization-based framework to determine and apply the appropriate DR strategies in a distribution system structure including a PV generation unit.

Author Contributions: S.G.: Conceptualization, Software, Data curation; A.K.E.: Writing-Original draft preparation, Visualization, Investigation; İ.Ş.: Conceptualization, Investigation; O.E.: Methodology, Software Validation, Writing-Reviewing and Editing; J.P.S.C.: Supervision, Writing-Reviewing and Editing. All authors have read and agreed to the published version of the manuscript.

Funding: J.P.S.C. acknowledges the support by FEDER funds through COMPETE 2020 and by Portuguese funds through FCT, under POCI-01-0145-FEDER-029803 (02/SAICT/2017).

Conflicts of Interest: The authors declare no conflict of interest.

\section{References}

1. Bompard, E.; Huang, T.; Wu, Y.; Cremenescu, M. Classification and trend analysis of threats origins to the security of power systems. Int. J. Electr. Power Energy Syst. 2013, 50, 50-64. [CrossRef]

2. Strasser, T.; Andrén, F.; Kathan, J.; Cecati, C.; Buccella, C.; Siano, P.; Leitão, P.; Zhabelova, G.; Vyatkin, V.; Vrba, P.; et al. A Review of Architectures and Concepts for Intelligence in Future Electric Energy Systems. IEEE Trans. Ind. Electron. 2015, 62, 2424-2438. [CrossRef]

3. European Commission: Renewable Energy. Available online: http://ec.europa.eu/energy/en/topics/renewableenergy (accessed on 14 June 2020).

4. 2030 Climate \& Energy Framework. Available online: https:/ec.europa.eu/clima/policies/strategies/2030_en (accessed on 1 October 2020).

5. Renewable Energy Prospects: China. IRENA, Remap 2030. November 2014. Available online: https://www.irena.org/-/media/Files/IRENA/Agency/Publication/2014/Nov/IRENA_REmap_China_ summary_2014_EN.ashx?la=en\&hash=807F1019E27CA5C3D36FBA445EC48F150D58A6B5 (accessed on 2 October 2020).

6. Yoo, T.H.; Kwon, H.-G.; Lee, H.C.; Rhee, C.-H.; Yoon, Y.T.; Park, J.-K. Development of reliability based Demand response program in Korea. ISGT 2011. [CrossRef]

7. US Energy Information Administration-Electric Utility Demand Side Management Archive. Available online: https:/www.eia.gov/electricity/data/eia861/dsm/ (accessed on 2 October 2020).

8. Wu, Q.; Wang, L.; Li, B. An optimized demand response strategy for electric water heaters and the associated impact on power system operational reliability. In Proceedings of the 2017 International Smart Cities Conference (ISC2), Wuxi, China, 14-17 September 2017; pp. 1-6. [CrossRef]

9. Gaspar, C.; Gomes, A. A contribution of demand response for the reliability of a power system. In Proceedings of the 2016 IEEE 16th International Conference on Environment and Electrical Engineering (EEEIC), Florence, Italy, 7-10 June 2016; pp. 1-6.

10. Qi, X.; Ji, Z.; Wu, H.; Zhang, J.; Wang, L. Short-term reliability assessment of generating systems considering demand response reliability. IEEE Access 2020, 8, 74371-74384. [CrossRef] 
11. Ribeiro, M.F.; Shafie-Khah, M.; Osório, G.J.; Hajibandeh, N.; Catalão, J.P.S. Optimal demand response scheme for power systems including renewable energy resources considering system reliability and air pollution. In Proceedings of the 2017 IEEE International Conference on Environment and Electrical Engineering and 2017 IEEE Industrial and Commercial Power Systems Europe (EEEIC/I\&CPS Europe), Milan, Italy, 6-9 June 2017; pp. 1-6.

12. Goel, L.; Wu, Q.; Wang, P. Reliability enhancement and nodal price volatility reduction of restructured power systems with Stochastic demand side load shift. In Proceedings of the 2007 IEEE Power Engineering Society General Meeting, Tampa, FL, USA, 24-28 June 2007; pp. 1-8.

13. Song, M.; Amelin, M.; Shayesteh, E.; Hilber, P. Impacts of flexible demand on the reliability of power systems. In Proceedings of the 2018 IEEE Power \& Energy Society Innovative Smart Grid Technologies Conference (ISGT), Washington, DC, USA, 19-22 February 2018; pp. 1-5.

14. Li, G.; Bie, Z.; Hua, B.; Wang, X. Reliability evaluation of distribution systems including micro-grids considering demand response and energy storage. In Proceedings of the 2012 47th International Universities Power Engineering Conference (UPEC), London, UK, 4-7 September 2012; pp. 1-6.

15. Zhou, P.; Chen, Z.; Yang, H.; Wen, L.; Liu, Y.; Hu, B.; Ma, Y.; Xia, Y.; Xiao, R.; Li, B. Reliability evaluation of grid-connected micro-grid considering demand response. In Proceedings of the 2016 International Conference on Probabilistic Methods Applied to Power Systems (PMAPS), Beijing, China, 16-20 October 2016; pp. 1-5.

16. Abogaleela, M.; Kopsidas, K. Reliability enhancements from demand response considering interrupted energy assessment rates. In Proceedings of the 2016 Eighteenth International Middle East Power Systems Conference (MEPCON), Cairo, Egypt, 27-29 December 2016; pp. 330-335.

17. Su, S.; Hu, Y.; He, L.; Yamashita, K.; Wang, S. An assessment procedure of distribution network reliability considering photovoltaic power integration. IEEE Access 2019, 7, 60171-60185. [CrossRef]

18. Altamimi, A.; Jayaweera, D. Reliability of power systems with climate change impacts on hierarchical levels of PV systems. Electr. Power Syst. Res. 2020, 190, 106830. [CrossRef]

19. Hamzeh, M.; Vahidi, B. Reliability evaluation of distribution transformers considering the negative and positive effects of rooftop photovoltaics. IET Gener. Transm. Distrib. 2020, 14, 3063-3069. [CrossRef]

20. Raghuwanshi, S.S.; Arya, R. Reliability evaluation of stand-alone hybrid photovoltaic energy system for rural healthcare centre. Sustain. Energy Technol. Assess. 2020, 37, 100624. [CrossRef]

21. Zou, K.; Mohy-Ud-Din, G.; Agalgaonkar, A.P.; Muttaqi, K.M.; Perera, S. Distribution System Restoration With Renewable Resources for Reliability Improvement Under System Uncertainties. IEEE Trans. Ind. Electron. 2020, 67, 8438-8449. [CrossRef]

22. Shi, S.; Lo, K.L. Reliability assessment of power system considering the impact of wind energy. In Proceedings of the 2012 47th International Universities Power Engineering Conference (UPEC), London, UK, 4-7 September 2012; pp. 1-6.

23. Fang, C.; Xiang, G.; Junwei, Y. Study on reliability assessment of composite generation and transmission system integrated wind farm. In Proceedings of the 2012 IEEE International Conference on Power System Technology (POWERCON), Auckland, New Zealand, 30 October-2 November 2012; pp. 1-5.

24. Manandhar, S. Reliability Assessment of Smart Distribution System and Analysis of Automatic Line Switches. Master's Thesis, The University of Tennessee, Chattanooga, TN, USA, 2013.

25. Distribution System Reliability Evaluation Services. Chapter 4. Available online: https://shodhganga. inflibnet.ac.in/bitstream/10603/10247/9/09_chapter\%204.pdf (accessed on 2 October 2020).

26. Mohagheghi, S.; Yang, F.; Falahati, B. Impact of demand response on distribution system reliability. In Proceedings of the 2011 IEEE Power and Energy Society General Meeting, Detroit, MI, USA, 24-28 July 2011; pp. 1-7.

27. Billinton, R.; Allan, R.N.; Snaith, E.R. Book Review of 'Reliability Evaluation of Power Systems'; Springer: New York, NY, USA, 1996.

28. Billinton, R.; Allan, R.N. Reliability Assessment of Large Electric Power Systems; Springer Science and Business Media LLC: Berlin/Heidelberg, Germany, 1988.

29. Balijepalli, N.; Venkata, S.; Richter, C.; Christie, R.; Longo, V. Distribution System Reliability Assessment Due to Lightning Storms. IEEE Trans. Power Deliv. 2005, 20, 2153-2159. [CrossRef]

30. Brown, R.E. Reliability Metrices and Indices. In Electric Power Distribution Reliability; CRC Press: New York, NY, USA, 2009; pp. 41-102. 
31. National Renewable Energy Laboratory-Measurement and Instrumentation Data Center. Available online: https://midcdmz.nrel.gov/ (accessed on 12 June 2020).

32. Topcu, S.; Dilmac, S.; Aslan, Z. Study of hourly solar radiation data in Istanbul. Renew. Energy 1995, 6, 171-174. [CrossRef]

33. Bulut, H. Generation of typical solar radiation data for Istanbul, Turkey. Int. J. Energy Res. 2003, 27, 847-855. [CrossRef]

34. Paterakis, N.G.; Santos, S.F.; Catalão, J.P.S.; Erdinç, O.; Bakirtzis, A.G. Coordination of smart-household activities for the efficient operation of intelligent distribution systems. In Proceedings of the IEEE PES Innovative Smart Grid Technologies (ISGT) European 2014 Conference, Istanbul, Turkey, 12-15 October 2014; pp. 1-6.

(C) 2020 by the authors. Licensee MDPI, Basel, Switzerland. This article is an open access article distributed under the terms and conditions of the Creative Commons Attribution (CC BY) license (http://creativecommons.org/licenses/by/4.0/). 